2011-01-01

\title{
The Diffusion of Microgeneration Technologies.: Assessing the Influence of Perceived Product Characteristics on Home Owners' Willingness to Pay
}

\author{
Marius Claudy \\ Technological University Dublin, mclaudy@tudublin.ie \\ Claus Michelsen \\ Hale Institute for Economic Research, Germany \\ Aidan O'Driscoll \\ Technological University Dublin, Aidan.odriscoll@tudublin.ie
}

Follow this and additional works at: https://arrow.tudublin.ie/buschmarart

Part of the Marketing Commons

\section{Recommended Citation \\ Claudy, M., Michelsen, C., O'Driscoll, A.: The diffusion of microgeneration Technologies:Assessing the influence of perceived product characteristics on home owners' willingness to pay. Energy Policy Forthcoming. Volume (Year): 39 (2011) Issue (Month): 3 (March) Pages: 1459-1469.}

This Article is brought to you for free and open access by the School of Marketing at ARROW@TU Dublin. It has been accepted for inclusion in Articles by an authorized administrator of ARROW@TU Dublin. For more information, please contact arrow.admin@tudublin.ie, aisling.coyne@tudublin.ie,gerard.connolly@tudublin.ie. Funder: Technological Sector Strand III program Energy Efficient Policy Research in Domestic Buildings

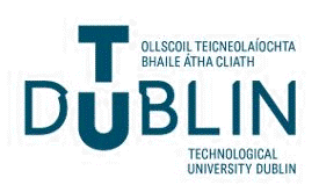




\section{AUTHOR QUERY FORM}

\begin{tabular}{|c|c|c|}
\hline 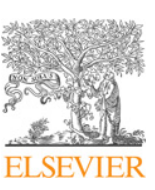 & $\begin{array}{l}\text { Journal: JEPO } \\
\text { Article Number: } 4670\end{array}$ & $\begin{array}{l}\text { Please e-mail or fax your responses and any corrections to: } \\
\text { E-mail: corrections.esil@elsevier.macipd.com } \\
\text { Fax: +44 } 1392285878\end{array}$ \\
\hline
\end{tabular}

Dear Author,

Please check your proof carefully and mark all corrections at the appropriate place in the proof (e.g., by using on-screen annotation in the PDF file) or compile them in a separate list.

For correction or revision of any artwork, please consult http://www.elsevier.com/artworkinstructions.

Any queries or remarks that have arisen during the processing of your manuscript are listed below and highlighted by flags in the proof. Click on the $\mathrm{Q}$ link to go to the location in the proof.

\begin{tabular}{|c|c|}
\hline $\begin{array}{l}\text { Location in } \\
\text { article }\end{array}$ & $\begin{array}{l}\text { Query / Remark: click on the Q link to go } \\
\text { Please insert your reply or correction at the corresponding line in the proof }\end{array}$ \\
\hline$\underline{\text { Q1 }}$ & $\begin{array}{l}\text { Reference(s) given here were noted in the reference list but are missing from the text - please position each } \\
\text { reference in the text or delete it from the list. }\end{array}$ \\
\hline$\underline{\mathrm{Q} 2}$ & In Table $2{ }^{\prime} *$ ' has not been explained. Please check. \\
\hline Q3 & Explanation to "**" is provided but the same is not cited in the body of the table. Please check. \\
\hline
\end{tabular}

Thank you for your assistance. 
The diffusion of microgeneration technologies assessing the influence of perceived product characteristics on home owners' willingness to pay

Marius C. Claudy ${ }^{\mathrm{a}, *}$, Claus Michelsen ${ }^{\mathrm{b}}$, Aidan O’Driscoll ${ }^{\mathrm{a}}$

${ }^{a}$ Faculty of Business, Dublin Institute of Technology, Aungier Street, Dublin 2, Ireland

- This study presents empirical insight into Irish home owners' willingness to pay (WTP) for microgeneration technologies and the relative influence of subjective consume perceptions. The findings presented in this study clearly show that a major reason for the slow uptake is home owners' WTP which is significantly below market prices. WTP for solar water heaters, which matches current sales figures in Ireland, is the only exception. In this context, public policy in the form of financial incentives such as grant aid or tax incentives can be very costly and might not provide a viable support mechanism for policy makers who aim to promote the diffusion of microgeneration. However, the results also suggest that home owners' WTP is not solely based on rational financial reasoning but is also influenced by people's subjective perception of the technologies' characteristics. - The findings can be used by marketers and policy makers to design alternative and more market-based support mechanism (e.g., consumer finance or leasing and fee-forservice models), which might prove more feasible solutions to promote microgeneration. 


\title{
The diffusion of microgeneration technologies assessing the influence of perceived product characteristics on home owners' willingness to pay
}

\author{
Marius C. Claudy ${ }^{\mathrm{a}, *}$, Claus Michelsen ${ }^{\mathrm{b}}$, Aidan O'Driscoll ${ }^{\mathrm{a}}$ \\ ${ }^{a}$ Faculty of Business, Dublin Institute of Technology, Aungier Street, Dublin 2, Ireland \\ ${ }^{\mathrm{b}}$ Department of Urban Economics, Halle Institute for Economic Research, D-06017 Halle (Saale), Germany
}

\section{A R T I C L E I N F O}

\section{Article history:}

Received 6 July 2010

Accepted 8 December 2010

\section{Keywords:}

Diffusion

Microgeneration technologies

Willingness to pay

\begin{abstract}
A B S T R A C T
This study presents empirical insight into willingness to pay (WTP) for microgeneration technologies and the relative influence of subjective consumer perceptions. First, we apply a double-bounded contingent valuation method to elicit Irish home owners' WTP for micro wind turbines, wood pellet boilers, solar panels and solar water heaters. Utilizing findings from the adoption of innovation literature, in a second step we assess the influence of antecedents on WTP for each of the four technologies, including (1) home owners' perception of product characteristics, (2) normative influences and (3) sociodemographic characteristics. Our results show that WTP varies significantly among the four technologies. More importantly, however, home owners hold different beliefs about the respective technologies, which significantly influence their WTP. The results provide valuable information for marketers and policy makers aiming to promote microgeneration technologies more effectively in consumer markets.
\end{abstract}

(c) 2010 Elsevier Ltd. All rights reserved.

\section{Introduction}

Under the umbrella of the European Commission's Energy Policy Roadmap and the Kyoto Protocol, Ireland has committed itself to ambitious energy targets. As outlined in its National Climate Change Strategy, ${ }^{1}$ Ireland has agreed to cut greenhouse gas emissions by $20 \%$ compared to 1990 levels by 2020. Further, Ireland set out the country's energy policy direction in its Energy White Paper (Department of Communications, Marine and Natural Resources, 2007), aiming to meet $33 \%$ of the country's total electricity consumption from renewable energy sources by 2020 . The Irish government is also aiming for a $12 \%$ market penetration of renewables in the heat market by 2020 .

In this context, the residential sector provides one of the greatest potentials to reduce overall energy demand and greenhouse gases. In 2008 this sector accounted for about $25 \%$ of the total primary energy requirements and $26 \%$ of energy-related $\mathrm{CO}_{2}$ emissions in Ireland. It was thus the second largest source of $\mathrm{CO}_{2}$ emissions after transport (O'Leary et al., 2008).

Whereas numerous regulations and energy standards have already led to significant improvements in energy efficiency of new buildings, the existing housing stock provides one of the greatest challenges for energy efficiency improvements and carbon emission reductions. For example, in 2005 Ireland's electricity usage per dwelling was $17 \%$ above EU-15 average and Irish houses

\footnotetext{
* Corresponding author. Tel.: +3531402 3041.

E-mail address: marius.claudy@dit.ie (M.C. Claudy).

${ }^{1}$ Available from $\langle$ www.environ.ie $\rangle$.
}

emitted $92 \%$ more $\mathrm{CO}_{2}$ than the average house in EU-15 countries (O’Leary et al., 2008).

Recent technological innovations have made it possible for home owners to retrofit their homes and generate their own electricity and heat by the use of microgeneration technologies such as photovoltaic (PV) panels, micro wind turbines, solar water heaters, wood pellet boilers, geothermal heat pumps or combined heat and power units (CHP), ${ }^{2}$ thus providing electricity and heat close to the source of consumption. Previous studies have shown that investment in microgeneration can be an economically viable ${ }^{3}$ way to reduce energy costs and $\mathrm{CO}_{2}$ emissions and can help to trigger positive changes in energy consumption patterns (e.g. Allen et al., 2008). Microgeneration has the potential to play an important part in reducing overall energy demand and $\mathrm{CO}_{2}$ emission in the residential sector and help Ireland meet its renewable energy targets.

In order to encourage the uptake of renewable energy and microgeneration, the Irish government introduced several support policies and information campaigns. Since early 2006 the Renewable Energy Feed-in Tariff (REFIT) has become the main tool for promoting renewable energy. The tariffs are guaranteed for up to 15 years, and so far large-scale wind farms have been the main beneficiaries. While REFIT is likely to have a significant impact on

\footnotetext{
${ }^{2}$ CHP is technically not a "renewable" but is included here as it has the potential to save significant amounts of energy and reduce carbon emissions.

${ }^{3}$ The economic potential of sustainable energy systems is largely theoretical, based on discount rates, life-cycle evaluations and current or expected energy prices.
}

0301-4215/\$ - see front matter (c) 2010 Elsevier Ltd. All rights reserved. doi:10.1016/j.enpol.2010.12.018 
the diffusion of renewable energies in electricity generation, it is questionable whether it will encourage Irish home owners, small businesses or communities to invest in microgeneration, as the reference prices for repayments to suppliers are relatively small. For example, the compensation for electricity from small-scale wind turbines is referenced at a price of $€ 0.19$ per $\mathrm{kWh} .{ }^{4}$ The main policy instrument to encourage the uptake of microgeneration technologies in the residential sector is grant aid, which for example is available to home owners via the Greener Home Scheme. ${ }^{5}$

Despite these policy efforts, the application of microgeneration technologies in Ireland remains low. For example, estimates from 2008 show that on-grid cumulative capacity of PV panels in the comparable jurisdictions of Austria and Denmark were 26,977 MWp and 2790 MWp respectively, compared to about $100 \mathrm{MWp}$ in Ireland (Observ'ER, 2009). Further, 2008 figures show that Austria had about $2,268,231 \mathrm{~kW}_{\text {th }}$ worth of solar thermal collectors installed and Denmark about 292,796 $\mathrm{kW}_{\mathrm{th}}$, compared to an estimated $50,080 \mathrm{~kW}_{\text {th }}$ in Ireland (ESTIF, 2009). ${ }^{6}$

The comparatively slow uptake of microgeneration technologies in Ireland suggests that home owners' willingness to pay (WTP) for microgeneration is significantly lower than actual market prices, posing a serious challenge for policy makers and marketers. More importantly, the figures imply that current grant schemes or feed-in tariffs are not able to bridge the gap between consumer WTP and actual market prices, providing scope for research on WTP of Irish home owners and their general perception of microgeneration technologies.

The objective of this study is therefore twofold. First, the study aims to address the lack of empirical evidence and to estimate home owners' willingness to pay for microgeneration technologies. The findings will highlight the gap between actual prices and home owners' WTP and emphasize differences in WTP between the technologies. Secondly, building on findings from the diffusion-ofinnovation literature, the study aims to investigate home owners' perceptions of product characteristics and their influence on WTP, providing valuable information for policy makers and marketers aiming to promote the uptake of microgeneration effectively.

The rest of this study is structured as follows. In the next section we discuss previous studies on WTP for green energy and microgeneration technologies and highlight some of their shortcomings. We then discuss WTP in the diffusion-of-innovation framework to identify antecedents of WTP and to formulate testable hypotheses. Next the survey methodology that was applied to estimate empirically Irish home owners' WTP and test the respective hypotheses is explained. We discuss the measurement of WTP and its underlying antecedents. This is followed by the results section, showing overall WTP for four microgeneration technologies and evaluating the influence of perceptions of product characteristics, normative influence and sociodemographic factors. Finally we discuss how policy makers can use this knowledge to promote microgeneration, increase consumers' WTP and thus reduce the costs of public policy.

\section{Literature}

Numerous studies in the area of renewable energy and microgeneration have tried to estimate consumers' willingness to pay

${ }^{4}$ Renewable Energy Feed in Tariff (RE-FIT-2006): a competition for electricity generation from biomass, hydro and wind. Available from Sustainable Energy Authority of Ireland (SEAI), 〈www.seai.ie >.

${ }^{5}$ Greener Homes Scheme: Homeowners. Available from SEAI, 〈www.seai.ie〉.

${ }^{6}$ There are admittedly differences in the sociopolitical and cultural environment between the three countries. The early introduction of relatively high feed-in tariffs was a key driver of the diffusion of microgeneration technologies in Denmark and Austria. for green electricity or microgeneration technologies and to evaluate consumers' underlying motivations and perceived barriers via contingent valuation methods or choice experiments. In regard to green energy, Hansla et al. (2008) for example evaluated Swedish households' willingness to pay for green electricity. Their results show that WTP increases with positive attitudes towards green electricity. Ek (2005) arrives at similar findings, showing that Swedish house owners have a generally positive attitude to wind power, which, however, decreases with age, income and information. Similarly to these findings, Zarnikau (2003) estimated willingness to pay for electric utility investments in renewable energy and energy efficiency resources, showing that sociodemographic factors such as age, education and salary had a significant impact on WTP. Evaluating WTP for green electricity in Korea, Yoo and Kwak (2009) demonstrate that households have a positive WTP for electricity coming from a renewable source. Nomura and Akai (2004) arrived at similar results, showing that Japanese consumers have a positive WTP for green electricity and that consumers who believe in the future success of renewable energy technologies have a higher WTP than others.

Broadly in line with these findings, a WTP study conducted by Batley et al. (2000) shows that willingness to pay more for green electricity in the UK depends on people's attitudes to and their experience with green energy sources. Borchers et al. (2007) estimated a positive WTP for electricity from green energy sources in the United States. However, results from a choice experiment suggest that WTP differs by source and that consumers prefer electricity from solar power to wind and biomass. In another choice study, Wiser (2007) explored WTP for renewable energy under collective and voluntary payment vehicles, and under government and private provisions of the good. The results clearly indicate that WTP is higher under a collective payment mechanism and under private provision.

The empirical evidence on microgeneration technologies is comparatively scarce. As far as the authors are aware, only one study has evaluated home owners' WTP for microgeneration and their underlying motivations. In a choice experiment, Scarpa and Willis (2010) investigated households' WTP for microgeneration technologies (i.e. solar PV, micro wind, solar thermal, heat pumps, biomass boilers and pellet stoves) in the UK. The relative influence of six attributes, including capital cost of the technology, home owners' energy bill, maintenance cost and inconvenience of the system, on home owners' WTP was evaluated. They further assessed differences in WTP depending on whether the respective technology was recommended by someone (e.g. friend or plumber) and different contract lengths. The results show that although microgeneration adoption is valued by households, WTP is not high enough to cover the actual capital cost of these technologies.

Whereas choice experiments provide important evidence on the utility consumers derive from product characteristics by revealing the trade-offs they are willing to make, it can be argued that this rational choice perspective fails to "incorporate the fact that individuals also utilize their emotional perspective and may choose to either ally or distance themselves to goods or services they like or dislike" (Faiers et al., 2007, p. 4386). Several studies have shown that consumers not only evaluate costs against benefits when faced with a buying decision, but are also influenced by their psychological, social and institutional environments (Spash et al., 2008). For example, studies evaluating WTP for wildlife (e.g. Ojea and Loureiro, 2007) or biodiversity (e.g. Spash et al., 2008) have challenged the rational choice assumption and shown that consumers' environmental and ethical beliefs have a positive influence on their WTP.

Kimenju and De Groote (2008) estimated consumers' WTP for genetically modified (GM) food in Kenya, incorporating the influence of consumers' subjective perceptions of GM food. 
1 The findings clearly show that perceived health risks or ethical concerns have a negative influence on people's WTP. In this context we argue that subjective perceptions of product attributes as well as social influences have a significant impact on consumers' willingness to pay for microgeneration technologies and should thus be included and empirically tested.

\section{Willingness to pay for microgeneration technologies}

The promotion of microgeneration technologies via public policy is likely to yield positive externalities. Microgeneration can play a vital role in reducing $\mathrm{CO}_{2}$ emissions, easing fossil fuel dependency and stabilizing energy costs (Energy Saving Trust, 2005).

The discussion above, however, has indicated that consumers are often not willing to pay for microgeneration; this poses serious challenges for policy makers aiming to stimulate the uptake of these technologies. The predominant policy support mechanism is simply to reduce costs for consumers via grants, subsidies or tax incentives (Sorrell et al., 2004). Such policies, however, can be very costly and place a heavy burden on taxpayers, and might even adversely affect public support for renewable energy. The recent debate in Germany is a good example. Local energy providers have estimated that government support for PV will cost German taxpayers about $€ 64$ billion, which translates into yearly costs of $€ 70$ per household (Frondel et al., 2010). Thus, there is a need for government to provide support for microgeneration as (cost-) efficiently as possible.

Empirical research on weatherization measures has shown that the success of subsidies or grants often depends on the way programmes are marketed and managed (Stern et al., 1986). What makes policies effective is the extent to which campaigns manage to capture the attention of the audience, gain their involvement and overcome possible skepticism (Stern, 1999).

Promoting microgeneration technologies as (cost-) efficiently as possible thus requires a thorough understanding of the consumer and the factors influencing their decision to adopt such new technologies (e.g. Hastings, 2007).

In the following subsections we take a closer look at consumers' adoption decisions and, in light of the empirical evidence, form testable hypotheses as to how perceptions affect home owners' WTP for microgeneration technologies.

\subsection{Diffusion of innovation perspective}

The discussion above has shown that microgeneration technologies provide innovative solutions for home owners to produce electricity and heat close to the source of consumption. In this study we define innovation as "an idea, practice or object perceived as new by the individual" (Rogers, 2003, p. 12). The definition clearly emphasizes potential adopters' perceptions as a key criterion for defining the newness of a product. As long as a technology is perceived as new, it can be labeled an innovation. For example, PV cells have been commercially available since the 1950 s, yet most consumers would regard them as an innovative technology to produce electricity. On the other hand, the definition indirectly suggests that a technological invention in itself cannot be considered an innovation. Only when consumers become aware of a new technology (i.e. through marketing efforts) can an invention be called an innovation. In other words, "a discovery that goes no further than the laboratory remains an invention" (Garcia and Calantone, 2002, p. 112).

From a consumer's perspective, the innovation decision process thus begins when an "individual (or other decision-making unit) is exposed to an innovation's existence and gains an understanding of how it functions" (Rogers, 2003, p. 171). According to
Rogers' model of the innovation decision process, this first stage is referred to as the knowledge stage and is followed by four stages: persuasion, decision, implementation and confirmation.

Gaining awareness of an innovation generally depends on personality variables and socioeconomic characteristics such as education or age. Some consumer segments appear to be generally more open to new ideas and "often function as strategically important target groups for marketers and policy makers to stimulate the diffusion of innovations like microgeneration technologies" (Claudy et al., 2010).

Persuasion is the next stage at which consumers, once aware of the innovation, evaluate characteristics such as relative advantages, complexity or initial price. On the basis of this assessment consumers form a favorable or unfavorable attitude to the new product, which ultimately results in a high or low intention to buy or WTP for the innovation (Rogers, 2003, p. 174). The perception of product characteristics is likely to vary, depending on the consumer and the type of product.

Next, this subjective evaluation of product characteristics leads to a decision whether to adopt or reject the innovation. If persuaded, consumers decide "to make full use of an innovation as the best course available" (Rogers, 2003, p. 177). On the implementation stage, consumers then actually purchase the innovation and assess its usefulness. This assessment leads to the confirmation stage, at which consumers decide whether or not to continue using the innovation.

It is important to note that throughout the adoption-decision process, consumers can be exposed to communication in the form of information or public policy campaigns. Understanding home owners' perceptions of microgeneration technologies and how they translate into WTP is therefore an important first step in the design of policies that aim to promote the uptake of microgeneration (cost-) efficiently in consumer markets.

\subsection{Perceived product characteristics}

As outlined above, home owners' evaluation of product characteristics is likely to yield low or high WTP for microgeneration technologies. The most commonly used product characteristics in innovation studies are relative advantage, compatibility, trialability, complexity and observability. According to Rogers (2003, p. 221), these attributes are likely to explain $49-87 \%$ of variation in adoption rates.

An innovation's relative advantage reflects "the degree to which an innovation is perceived as being better than the idea it supersedes" (Rogers, 2003, p. 15). The usefulness of this attribute in innovation studies has, however, been questioned. Tornatzky and Klein (1982), for example, argue that relative advantage can convey almost anything, from economic profitability to social benefits or time saved. They point out that "typically, [relative advantage] is the garbage pail characteristic in innovation characteristic studies into which any of a number of innovation characteristics are dumped" and conclude that "relative advantage studies lack conceptual strength, reliability, and prescriptive power" (p. 34). More recent empirical studies on green innovations tend to confirm this, showing that consumers associate various advantages with microgeneration and energy efficiency measures, including energy cost savings (e.g. Nyrud et al., 2008), environmental friendliness (e.g. Schwarz and Ernst, 2008 ) or independence from conventional sources of fuel (e.g. Hübner and Felser, 2001). Since energy-cost savings were provided to consumers in the subsequent WTP experiment, the focus falls on the last two constructs, and we argue that

$\mathbf{H}_{1 \mathbf{a}}$. Perceived environmental friendliness has a positive effect on home owners' willingness to pay for microgeneration technologies. 
$\mathbf{H}_{\mathbf{1} \text { b. }}$ Perceived independence has a positive effect on home owners' willingness to pay for microgeneration technologies.

The second product characteristic is compatibility, which is defined as "the degree to which an innovation is perceived as being consistent with existing values, needs, and past experiences of the potential adopter" (Rogers, 2003, p. 15). Berkowitz and Haines (1980), for example, found in their study that adopters of solar water heating systems associated greater compatibility with the respective technology than non-adopters. Nevertheless, compatibility has been criticized as lacking a clear definition and operational clarity, as it refers to three different dimensions: values, needs and past experiences. Karahanna et al. (2006), for example, identified 15 different conceptualizations of compatibility in the information system adoption literature alone. In their meta-review, Karahanna et al. highlight an important dimension of compatibility that is particularly relevant for microgeneration technologies: compatibility with existing practices or habits and routines. According to Tornatzky and Klein (1982, p. 33), compatibility with existing practices "suggests a more practical or operational compatibility (compatibility with what people do)". This dimension is relevant, as heating and electricity production is usually detached from people's daily practices, and potential adopters might worry that operating a microgeneration technology would require them to change daily habits and routines. Thus, we argue that

$\mathbf{H}_{2}$. Perceived compatibility with habits and routines has a positive effect on home owners' willingness to pay for microgeneration technologies.

Third, complexity refers to "the degree to which an innovation is perceived as being difficult to use or understand" (Rogers, 2003, p. 16). Most microgeneration technologies are high-involvement products, requiring significant cognitive efforts on the part of the consumers in order to understand fully the novelty and usability of these innovations. Research has shown that in the case of highcomplexity products, people often value novel attributes negatively because of the anticipated high learning costs involved (e.g. Mukherjee and Hoyer, 2001). Thus, complexity associated with an innovation can ultimately result in lower WTP. Labay and Kinnear (1981) for example, compared consumers' perceptions of solar energy systems and found that non-adopters perceived such systems as significantly more complex. We therefore argue that

$\mathbf{H}_{3}$. Perceived complexity has a negative effect on home owners' willingness to pay for microgeneration technologies.

Trialability is the fourth attribute and stands for "the degree to which an innovation may be experimented with before adoption" (Rogers, 2003, p. 16). For example, in their study on water-saving devices, Schwarz and Ernst (2008) found that trialability had a positive impact on people's intention to adopt these innovations. Although most microgeneration technologies are impossible to try out before buying them, some home owners might be able to see these technologies working at a neighbor's or a friend's home, allowing them to make a more informed decision. Thus

$\mathbf{H}_{4}$. Perceived trialability has a positive effect on home owners' willingness to pay for microgeneration technologies.

Observability defines "the degree to which the results of an innovation are visible and communicable to others" (Rogers, 2003 , p. 16). The definition indirectly refers to how the innovation is perceived by other people, and it can be argued that social approval or subjective norms might be a more suitable construct. The latter reflect the perceived social influence through significant others such as friends, family or neighbors (e.g. Ajzen, 1991). Their opinion about the innovation can be considered a normative influence on a person's decision to adopt a microgeneration technology. Behavior that goes against the perceived subjective norm may result in feelings of "shame and self-reproach" (Pollard et al., 1999). Home owners who experience a strong support or favorable opinion for microgeneration among their friends and families are hence more likely to have a higher WTP. Thus

$\mathbf{H}_{5}$. Perceived subjective norms have a positive effect on home owners' willingness to pay for microgeneration technologies.

Rogers' (2003) scheme of product characteristics, however, have often been criticized of excluding some important attributes. Darley and Beniger (1981), for example, extended Rogers' scheme and suggested including the perception of capital cost of the innovation. Yet, since capital costs were provided to consumers in the WTP experiment alongside energy cost savings, we did not include them as an independent variable.

However, microgeneration technologies often require home owners to modify the existing infrastructure (i.e. house) significantly to fit the new technology. These hidden costs also include the level of disruption caused by potential building works and are likely to vary depending on the compatibility of the house (e.g. Schwarz and Ernst, 2008); we therefore argue that

$\mathbf{H}_{6}$. Perceived compatibility-related costs have a negative effect on home owners' willingness to pay for microgeneration technologies.

Another well-established concept in the innovation literature is perceived risk, which refers to consumers' evaluation of the likelihood of negative outcomes associated with an innovation (Kleijnen et al., 2009, p. 347). Various studies distinguish between three main types of risk - economic, functional and social risk that consumers have associated with innovations (e.g. Dholakia, 2001; Kleijnen et al., 2009; Peter and Tarpey, 1975; Stone and Grønhaug, 1993). Economic risk reflects the fear of wasting financial resources whereas functional risk refers to performance uncertainties of a new product. Finally, social risk reflects uncertainty as to how adopting the innovation might be perceived by relevant others. In the case of microgeneration, performance and financial risk are two sides of the same coin, as the performance highly determines the financial viability of the technology. In this study, perceived risk thus refers to uncertainty related to the performance (i.e. reliability) and the perceived social approval associated with the technology.

$\mathbf{H}_{\text {7a. }}$ Perceived performance risk has a negative effect on home owners' willingness to pay for microgeneration technologies.

H $_{\text {7b. }}$ Perceived social risk has a negative effect on home owners' willingness to pay for microgeneration technologies.

Whereas consumers' subjective perceptions of product characteristics are likely to have an influence on their WTP, sociodemographic variables should not be neglected and are discussed in the following subsection.

\subsection{Sociodemographic factors}

Various studies have shown that certain consumer segments are more likely to adopt microgeneration technologies, renewable energy or energy efficiency measures. For example, in a housing study in Ireland, O'Doherty et al. (2008) investigated determinants of domestic ownership of energy-saving devices. Their results clearly show that the adoption of energy-efficient devices is positively influenced by age and level of income. A study by Zarnikau (2003) arrives at similar results. The study shows that the willingness to pay for electric utility investments in renewable energy is highly influenced by the respondent's age and 
1 education. In this study we therefore decided also to control for differences in WTP between sociodemographic groups, segmenting home owners by age, gender, education, social class, type of ownership, household size and region. Another important factor often mentioned in innovation studies is knowledge (e.g. Nyrud et al., 2008; Arkesteijn and Oerlemans, 2005), which was also included in this study. ${ }^{7}$ Further, we were interested in whether people living in different types of houses have different WTP, and thus controlled for age, type and energy efficiency of the dwelling.

\section{Research methodology}

\subsection{Survey design and sample}

In order to test the above hypotheses empirically, data were collected through a field survey of home owners in the Republic of Ireland. The survey and sampling frame were developed in close cooperation with the Sustainable Energy Authority of Ireland (SEAI). Thanks to substantial external funding, a professional market research company was employed to carry out the data collection from November to December 2009. After discussions with academics and representatives from the market research company, computer-assisted telephone interviews (CATI) were chosen as the most appropriate mode of data collection. A preliminary study indicated low levels of awareness for heat pumps and micro CHP among the Irish population ${ }^{8}$ (Claudy et al., 2010) and we thus decided to focus on four microgeneration technologies: solar panels, micro wind turbines, solar water heating systems and wood pellet boilers. Each respondent was asked about only one of the four technologies.

CATI allowed us to utilize an adaptive survey design to identify the respective target population, which was home owners in the Republic of Ireland who are aware of the technology in question and who are partly or fully responsible for making financial decisions regarding the house they currently live in. As discussed above, awareness is a prerequisite of persuasion, and home owners who had not seen or heard of the technology in question were not interviewed. Using a quota sampling approach, the final sample of 1012 respondents was split equally across the four technologies. The quotas were based on region, gender and age to ensure an overall approximation of the overall population and, more importantly, comparability of subsamples for each technology. Table 1 shows that gender, age and regional splits are reasonably similar between subsamples and the overall population.

The questionnaire was split into four parts and designed following the guidelines of Arrow et al. (1993), which were developed under the US National Oceanic and Atmospheric Administration (NOAA). Whereas the first part of the questionnaire aimed to identify the target group defined above, in the second part suitable respondents were asked about their perceptions of characteristics of the respective microgeneration technology. In the third section, respondents were asked about their WTP for the technology, using a double-bounded contingent valuation approach (see Section 4.3). In the final part, respondents were asked about their sociodemographic background.

\footnotetext{
${ }^{7}$ As true or objective knowledge is difficult to assess, we asked home owners about their subjective knowledge, which can be defined as "a person's perception of the amount of information about a product class stored in his or her memory" (Klerck and Sweeney, 2007, p. 174).

${ }^{8}$ Levels of awareness based on a nationally representative survey conducted in March 2009: micro CHP, 18\%; ground source heat pumps, $45 \%$; wood pellet boilers, 58\%; micro wind turbines, 66\%; solar thermal heaters, $75 \%$ and solar panels, $80 \%$.
}

Table 1

Comparison of samples with population of Irish home owners (\%).

\begin{tabular}{llllll}
\hline Variable & $\begin{array}{l}\text { Wood } \\
\text { pellet } \\
\text { boilers } \\
(\boldsymbol{n}=\mathbf{2 4 1})\end{array}$ & $\begin{array}{l}\text { Small } \\
\text { wind } \\
\text { turbines } \\
(\boldsymbol{n}=\mathbf{2 3 4})\end{array}$ & $\begin{array}{l}\text { Solar } \\
\text { panels } \\
(\boldsymbol{n}=\mathbf{2 2 7})\end{array}$ & $\begin{array}{l}\text { Solar } \\
\text { water } \\
\text { heaters } \\
(\boldsymbol{n}=\mathbf{2 2 4})\end{array}$ & $\begin{array}{l}\text { Population } \\
\text { of Irish } \\
\text { home } \\
\text { owners }\end{array}$ \\
\hline $\begin{array}{l}\text { Gender } \\
\text { Male }\end{array}$ & 55.2 & 51.2 & 46.7 & 51.3 & 50.0 \\
Female & 44.8 & 48.8 & 53.3 & 48.7 & 50.0 \\
Age group & & & & & \\
15-24 & 0.8 & 3.0 & 2.6 & 2.2 & 20.0 \\
25-34 & 18.7 & 20.1 & 12.8 & 16.1 & \\
35-44 & 20.3 & 19.7 & 23.3 & 20.5 & 45.0 \\
$\begin{array}{l}\text { 45-59 } \\
\text { 60+ }\end{array}$ & 36.9 & 34.6 & 33.0 & 31.7 & \\
Region & 23.2 & 22.6 & 28.2 & 29.5 & 35.0 \\
Dublin & 19.9 & 21.4 & 20.7 & 20.5 & 24.0 \\
Rest of & 32.0 & 29.1 & 30.0 & 30.4 & 28.0 \\
Leinster & & & & & \\
Munster & 27.4 & 29.5 & 28.2 & 28.1 & 28.0 \\
Connacht/ & 20.7 & 20.1 & 21.1 & 21.0 & 20.0 \\
Ulster & & & & & \\
\hline
\end{tabular}

a The population data for home owners in Ireland stem from the market research company's own calculations and data from the Central Statistics Office (CSO) in Ireland. The age categories for the population data are 35-54 and 55+ cannot be compared directly.

\subsection{Measurement of perceptions}

The perceptions of microgeneration characteristics and subjective norms discussed above were elicited by asking home owners how strongly they agreed or disagreed with 27 statements, including 21 on product characteristics and three on subjective norms. Additionally, knowledge was measured using three statements. All statements were adapted from existing measures (see Appendix A) and formatted on a five-point Likert scale stretching from "strongly disagree" (1) to "strongly agree" (5). Knowledge was also measured on a five-point Likert scale, stretching from "very unfamiliar" (1) to "very familiar" (5). For the analysis, the scores were averaged to form an index for the respective constructs. The questions used to form the respective indices were first tested for internal reliability and all Cronbach's $\alpha$ values were significantly beyond the threshold of 0.7 (Nunnally, 1978). The only exception was trialability (0.68), which was however close to the threshold and therefore included in the analysis.

For relative advantage, two benefit indices were formed: environmental friendliness $\left(\mathrm{EF}_{\mathrm{BI}}\right)$ and independence $\left(\mathrm{I}_{\mathrm{BI}}\right)$. Perceptions of hidden costs were measured in the compatibility-related cost index $\left(\mathrm{CC}_{\mathrm{I}}\right)$. The perceptions of complexity $\left(\mathrm{C}_{\mathrm{I}}\right)$, trialability $\left(\mathrm{T}_{\mathrm{I}}\right)$ and compatibility with habits and routines $\left(\mathrm{HR}_{\mathrm{CI}}\right)$ were captured in three individual indices. Home owners' risk perceptions were divided into risk relating to performance $\left(P_{R I}\right)$ and social risk $\left(\mathrm{S}_{\mathrm{RI}}\right)$. The perception of normative influences was captured in a subjective norms index $\left(\mathrm{SN}_{\mathrm{I}}\right)$. Finally, knowledge $\left(\mathrm{K}_{\mathrm{I}}\right)$ was also measured as an index.

Table 2 clearly shows differences in the average perception of product characteristics associated with microgeneration technologies. For example, the mean scores suggest that on average more home owners seem to perceive microgeneration technologies as environmentally friendly $\left(\mathrm{EFB}_{\mathrm{I}}\right)$ than make them independent from conventional forms of energy $\left(\mathrm{IB}_{\mathrm{I}}\right)$. Further, the scores indicate that home owners perceive these technologies differently. For example, the mean scores imply that compared to the other technologies, fewer people believe that wood pellet boilers are compatible with their habits and routines $\left(\mathrm{HRC}_{\mathrm{I}}\right)$. The more 
Descriptive statistics of consumers' perceptions of product characteristics, subjective norms and knowledge. 3 Source: Own calculations.

Perceptions indices

$C^{\prime} \alpha^{\mathrm{a}}$

Wood pellet boiler Small wind turbine Solar panels
$(n=253)$

$(n=254)$

Mean SD Mean SD

interesting question, however, is how these perceptions influence home owners' WTP for the respective technologies.

\subsection{Measurement of willingness to pay}

In order to elicit Irish home owners' WTP for microgeneration technologies, we applied a contingent valuation (CV) approach. $\mathrm{CV}$ is a stated preference method that generally uses information from survey data and is commonly applied to investigate WTP for non-market goods. Revealed preference methods such as the hedonic pricing approach, on the other hand, are based on actual choice decisions that are directly observable in the market place (e.g. Louviere et al., 2000; Verhoef and Franses, 2002). In theory, either method could be used to estimate WTP for the microgeneration technologies discussed above. However, due to the small number of Irish households that have installed microgeneration technologies, applying a revealed preference method would be very difficult and stated preference methods such as $\mathrm{CV}$ are more feasible to estimate home owners' WTP.

In this CV study we utilized a double-bounded dichotomous choice format, which has several advantages over open-ended questions or single-bounded formats. Open-ended questions, for example, allow people to state their WTP directly and are thus easy to analyze. However, respondents often find it difficult to state their WTP for goods they are not familiar with. This can lead to extremely high or low stated WTP or non-response, which can cause spurious results (e.g. Haab and McConnell, 2003). Further, strategic behavior such as "protest votes" (i.e. zero WTP) are statistically inseparable from real zero WTP and can also lead to skewed results (e.g. Mitchel and Carson, 2003).

Close-ended questions, in which respondents are asked to accept or reject a given price offer, are therefore closer to everyday buying decisions and have become the more widely used method in CV studies (e.g. Schultz and Lindsay, 1990). Closeended questions can be single-bounded, double-bounded or multi-bounded. In single-bounded format respondents are offered a single bid (i.e. one price for a specific product) in a dichotomous yes/no answer format. From a utility-maximizing perspective, respondents are expected to accept the bid provided that the price is smaller than or equal to the person's reservation price. Yet researchers have shown that single-bounded formats are often statistically inefficient and require relatively large sample sizes. Hanemann et al. (1991) thus proposed to use double-bounded formats to investigate WTP for non-market goods. Depending on whether or not a respondent accepted the first bid, a second question offers a higher or lower bid to the respondents. Several studies have shown that this approach includes more information about WTP and improves efficiency of the WTP measures, including smaller confidence intervals of mean and median WTP (e.g. Carson et al., 1986; Hanemann et al., 1991). Double-bounded approaches have also been applied to measure WTP for renewable energies (e.g. Koundouri et al., 2009; Nomura and Akai, 2004). In recent studies multiple-bounded or polychotomous approaches were tested, but efficiency gains from (e.g.) a third question appear to be minuscule (e.g. Cooper and Hanemann, 1995). Further, Scarpa and Bateman (1998) point out that small efficiency gains come at costs (e.g. response effects) that are likely to offset the benefits of including a third question. We therefore decided to employ a double-bounded dichotomous choice format in order to investigate Irish home owners' WTP for solar panels, micro wind turbines, solar water heaters and wood pellet boilers.

\subsection{Payment vehicle}

In the valuation scenario we presented home owners with actual cost figures for the respective microgeneration technologies. In the scenario we told respondents that installing the microgeneration technology on/at their house would result in average annual energy cost savings of about $€ 500$ ( $€ 200$ for solar thermal collectors). Further, we pointed out that the energy produced comes from a renewable source and would thus reduce the greenhouse gas emissions of their household. Respondents were then asked if, in consideration of their household's income and expenditure, they would be willing to pay one of $€ 2000$, $€ 5000, € 7000, € 10,000$ or $€ 15,000$. Those who answered "yes" to the first question were then presented with a next higher amount and asked if they would pay $€ 5000, € 7000, € 10,000, € 15,000$ or $€ 20,000,{ }^{9}$ respectively. Home owners who answered "no" were asked if they were willing to pay $€ 1000, € 2000, € 5000, € 7000$ or $€ 10,000$, respectively. In order to minimize starting point bias, respondents were randomly assigned to one of the five starting bid levels.

\footnotetext{
${ }^{9}$ A qualitative pilot study in the form of face-to-face interviews with 20 Irish
} home owners had revealed a maximum WTP of $€ 20,000$. 


\section{Empirical model}

As noted above, respondents are faced with two bids, where the response to the first bid $\left(B_{i}\right)$ determines the level of the second bid (i.e. $B_{i}^{u}$ if $B_{i}$ accepted; and $B_{i}^{l}$ if $B_{i}$ rejected). Thus, there are four possible outcomes to the WTP questionnaire: $\pi^{y y}$ for accepting both bids, $\pi^{n n}$ for rejecting both bids, $\pi^{y n}$ for accepting the first bid and rejecting the second and $\pi^{n y}$ for rejecting the first bid and accepting the second. Following Hanemann et al. (1991), the probabilities for each outcome can be denoted as

$$
\pi^{y y}\left(B_{i}, B_{i}^{u}\right)=1-G\left(B_{i}^{u} ; \theta\right)
$$

$\pi^{n n}\left(B_{i}, B_{i}^{l}\right)=1-G\left(B_{i}^{l} ; \theta\right)$

$\pi^{y n}\left(B_{i}, B_{i}^{u}\right)=G\left(B_{i}^{u} ; \theta\right)-G\left(B_{i} ; \theta\right)$

$\pi^{n y}\left(B_{i}, B_{i}^{l}\right)=G\left(B_{i} ; \theta\right)-G\left(B_{i}^{l} ; \theta\right)$

where $G\left(B_{i} ; \theta\right)$ is the cumulative normal or logistic probability distribution of the bid with the parameter vector $\theta$. Assuming $N$ respondents to the $\mathrm{CV}$ questionnaire, the log-likelihood function for the responses can be written as

$$
\begin{aligned}
\ln L(\theta)= & \sum_{i=1}^{N}\left\{d_{i}^{y y} \ln \left[1-G\left(B_{i}^{u} ; \theta\right)\right]+d_{i}^{n n} \ln \left[1-G\left(B_{i}^{l} ; \theta\right)\right]\right. \\
& \left.+d_{i}^{y n} \ln \left[G\left(B_{i}^{u} ; \theta\right)-G\left(B_{i} ; \theta\right)\right]+d_{i}^{n y} \ln \left[G\left(B_{i} ; \theta\right)-G\left(B_{i}^{l} ; \theta\right)\right]\right\}
\end{aligned}
$$

where $d_{i}^{y y}, d_{i}^{n n}, d_{i}^{y n}$ and $d_{i}^{n y}$ are binary coded variables (e.g. if the $i$ th is "yes"/"yes", $d_{i}^{y y}=1$ and zero otherwise). The $M L$ estimator for the model $\hat{\theta}$ defined above is the solution for the first-order condition:

$\partial \ln L(\hat{\theta}) / \partial \theta=0$

There has been much discussion about the appropriate way to model double-bounded CV settings. Econometricians have argued that a prerequisite for using interval-data models, introduced for CV analysis by Carson et al. (1986) and Hanemann et al. (1991), is the perfect correlation of the error term $\rho=1$. However, the assumption that responses to the two bids follow the same true underlying valuation was questioned by Cameron and Quiggin (1994, p. 219) and empirical tests show that this assumption is in fact regularly violated (e.g. Aprahamian et al., 2007; DeShazo, 2002; Ready et al., 1996).

As an alternative, econometricians have suggested the use of bivariate probit models, in which a bivariate normal distribution $\Phi\left(B_{i 1}, B_{i 2}, \theta_{1}, \theta_{2}, \rho\right)$ is assumed, while $B_{i 1}$ and $B_{i 2}$ are the first and second bids and $\rho$ is the correlation between the error terms (e.g. Cameron and Quiggin, 1994). Several studies have compared the statistical efficiency of the more general bivariate probit model with the more restricted interval-data model and concluded that ideally both variants should be tested and the interval-data model should be applied when $\rho$ is sufficiently large (e.g. Alberini, 1995; Haab and McConnell, 2003). ${ }^{10,11}$

Following this approach, we start our statistical analysis by applying a bivariate probit model, testing for equality of the

\footnotetext{
${ }^{10}$ Alberini (1995) found that the results for the interval-data model are robust for values of $\rho<1$.

${ }^{11}$ When parameters in the bivariate model are restricted to be equal and the estimated correlation coefficient is statistically indistinguishable from zero, the model turns out to be an interval-data model. When the estimated correlation coefficient is statistically significant and different from zero while the parameters are equal, the model is a random effects probit model (Haab and McConnell, 2003).
}

Table 3

Estimated willingness to pay for microgeneration technologies.

\begin{tabular}{|c|c|c|c|c|c|}
\hline Measure & WTP & LB & UB & ASL & $\mathrm{CI} /$ mean \\
\hline \multicolumn{6}{|c|}{ Wood pellet boilers } \\
\hline Mean & 5380.14 & 4556.02 & 7045.61 & 0.0000 & 0.46 \\
\hline Median & 3476.31 & 2843.75 & 4097.03 & 0.0000 & 0.36 \\
\hline \multicolumn{6}{|c|}{ Small wind turbines } \\
\hline Mean & 8424.49 & 6801.94 & $12,839.40$ & 0.0000 & 0.72 \\
\hline Median & 5431.42 & 4618.97 & 6384.63 & 0.0000 & 0.33 \\
\hline \multicolumn{6}{|c|}{ Solar panels } \\
\hline Mean & 6207.80 & 5293.44 & 8003.34 & 0.0000 & 0.44 \\
\hline Median & 4230.95 & 3495.58 & 4972.38 & 0.0000 & 0.35 \\
\hline \multicolumn{6}{|c|}{ Solar water heaters } \\
\hline Mean & 3839.11 & 3256.23 & 4920.38 & 0.0000 & 0.43 \\
\hline Median & 2379.65 & 1729.57 & 2964.57 & 0.0000 & 0.52 \\
\hline
\end{tabular}

Source: Own calculations. Krinsky and Robb (95\%) confidence intervals for WTP measures (10.000 reps).

** Achieved significance level for testing $\mathrm{H}_{0}$ : WTP $\leq 0$, versus $\mathrm{H}_{1}$ : WTP $>0$.

parameters across equations and, when justifiable statistically, restrict them to be equal. In order to calculate the mean and median WTP and the respective confidence intervals, we employ the method introduced by Krinsky and Robb (1986), which was found to be robust, particularly for small to medium sample sizes (e.g. Cooper, 1994).

\section{Results}

\subsection{Willingness to pay}

The estimations presented in Table 4 were used to determine the mean and median WTP for the individual technologies, presented separately in Table 3. The results suggest that WTP varies significantly among the four technologies. Comparing Irish home owners' median WTP, ${ }^{12}$ the results clearly show that WTP for solar water heater is the lowest, at about $€ 2380$. This is not surprising, as we presented respondents in the valuation scenario with a significantly lower annual energy-cost savings figure of $€ 200$ for solar water heaters compared to $€ 500$ for the other microgeneration technologies. The median WTP for micro wind turbines, solar panels and wood pellet boilers is $€ 5431, € 4231$ and $€ 3476$, respectively.

The real costs for microgeneration technologies are significantly higher. According to the SEAI (2010), the average costs for installing a wood pellet boiler lie between $€ 10,000$ and $€ 16,000$. Further, a $5 \mathrm{kWh}$ micro wind turbine or a $3 \mathrm{kWh}$ solar panel system costs between $€ 20,000$ and $€ 25,000$. Solar water heating systems can be installed for approximately $€ 2400-€ 5000$.

The results have two important implications. First, the estimates clearly indicate that Irish home owners' WTP for microgeneration technologies is significantly lower than actual market prices, which confirms recent findings from the UK (Scarpa and Willis, 2010). The only exceptions are solar water heaters, for which WTP appears to be close to market prices. These results also confirm sales figures in Ireland, which for example show that

\footnotetext{
12 The median WTP was chosen since the mean is more affected by outliers (i.e. high bidding values), which can give excessive weight to a few respondents with exceptionally high WTP. Some scholars have therefore argued that the median "is arguably the better predictor of what the majority of people would actually be willing to pay" (Pearce et al., 2006, p. 118).
} 
Estimation results: influence of independent variables on willingness to pay.

Source: own calculations, by individuals' clustered standard errors in parentheses.

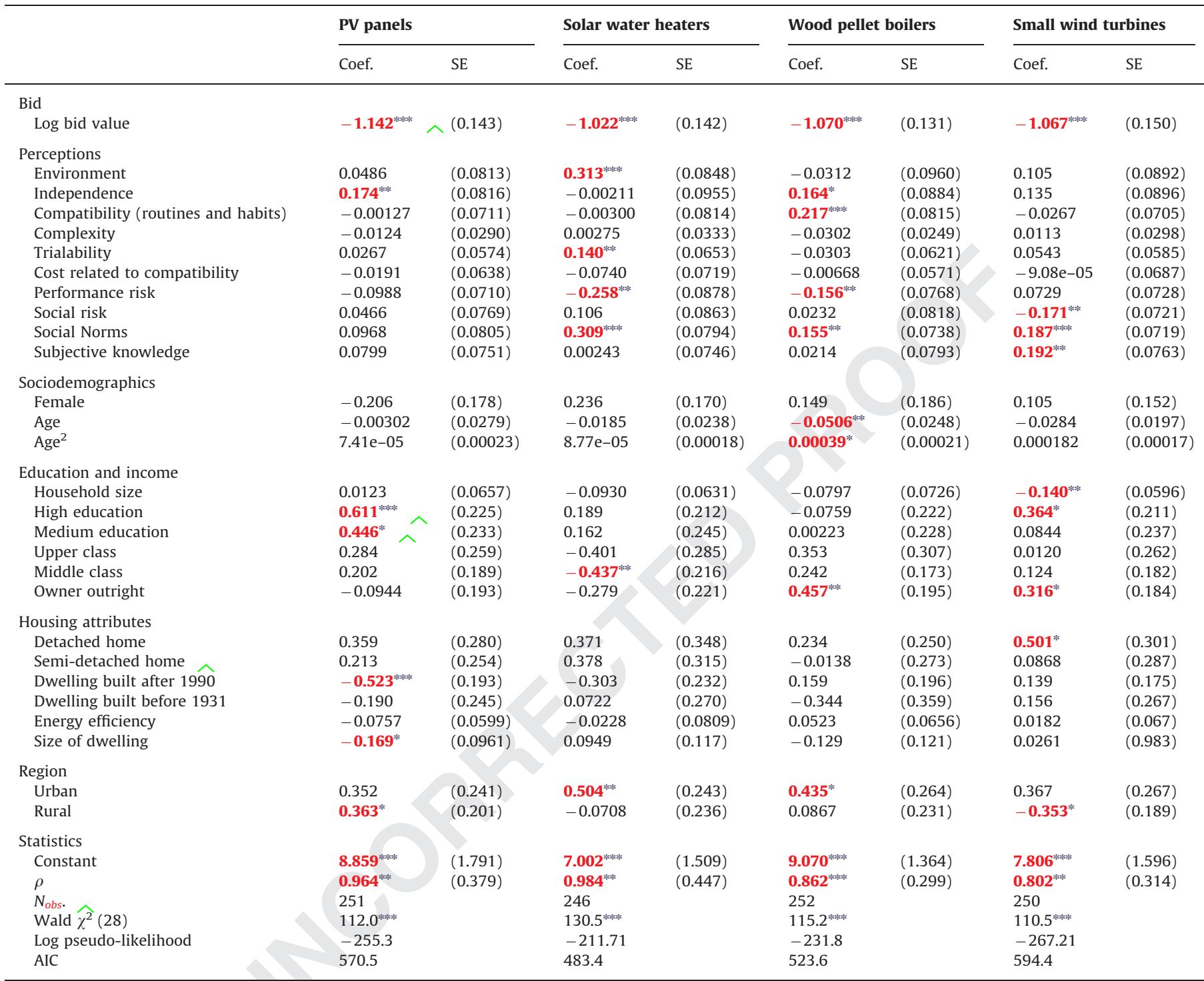

* * wele $p<0.01$

** $p<0.05$.

$* p<0.1$.

under the Greener Home Scheme, solar water heaters are by far the most installed microgeneration technology. ${ }^{13}$

Second, the results suggest that home owners' WTP is not solely based on rational financial reasoning. The payment vehicle in the CV study was the same across solar panels, micro wind turbines and wood pellet boilers. We would thus expect WTP to be fairly equal across technologies, yet the figures vary significantly. Further, the monthly energy cost saving for solar water heaters was only $€ 200$ (compared to $€ 500$ for the other scenarios), but surprisingly home owners are willing to pay disproportionately more for this technology. This is reflected in the average accepted payback period, which is approximately 12 years for solar water heaters and only 11, 9 and 7 years for micro wind turbines, solar panels and wood pellet boilers, respectively. Again, the findings indicate that home owners' WTP is not entirely based on rational cost-benefit evaluations but is likely to be influenced by

\footnotetext{
13 〈www.seai.ie/Grants/GreenerHomes/Scheme_Statistics〉.
}

subjective perceptions of the technologies' characteristics, people's personal background and social environment.

\subsection{Influence of subjective perceptions, sociodemographic factors and subjective norms}

The overall results from the bi-probit model ${ }^{14}$ are presented in Table 4. The estimates show that home owners perceive the four technologies very differently, (partly) explaining differences in WTP.

Regarding the perceptions of advantages $\left(\mathrm{H}_{1}\right)$, the results indicate that home owners who believe that investing in

${ }^{14}$ Following Alberini (1995), we started our analysis by applying unrestricted bivariate probit models. Because the Wald tests failed to reject the hypothesis of equality of coefficients (for all models), we restricted them to be equal across equations and re-estimated the models presented in Table 4. The Wald Test indicates high overall significance and was found to be significantly different from zero. Thus, we employed random effects probit models that were first applied to CV studies by Alberini et al. (1997). 
1 microgeneration technologies will make them independent from conventional fuels and energy suppliers have a higher WTP for wood pellet boilers and solar panels. Solar water heaters, on the other hand, appear to be more associated with environmental friendliness, which also translates into higher WTP.

Perceived compatibility with habits and routines $\left(\mathrm{H}_{2}\right)$ translates into a higher WTP only for wood pellet boilers. This result is not surprising, since operating a wood pellet boiler (i.e. ordering, storing and providing the fuel) requires considerable effort on the part of the home owner. Solar panels or wind turbines, on the other hand, once installed do not require additional work on the part of the home owner.

The perception of social risk $\left(\mathrm{H}_{7 \mathrm{~b}}\right)$ associated with micro wind turbines has a negative impact on home owners' WTP. This result is not surprising, since wind turbines are arguably the most visually intrusive technology and home owners might fear upsetting neighbors or local residents. On the other hand, home owners who experience strong support for microgeneration technologies from significant others such as friends and family $\left(\mathrm{H}_{5}\right)$ have a higher WTP for wind turbines, and also for wood pellet boilers and solar water heaters. Further, home owners who stated that they know someone who operates a solar water heater $\left(\mathrm{H}_{4}\right)$ had a higher WTP, which again highlights the importance of social influences for the diffusion of microgeneration technologies.

Uncertainty related to the performance of the technology $\left(\mathrm{H}_{7 \mathrm{a}}\right)$ has a negative influence on WTP for solar water heaters and wood pellet boilers, yet does not affect WTP for solar panels and wind turbines. Home owners' perceptions of (potential) compatibilityrelated costs $\left(\mathrm{H}_{6}\right)$ as well as perceived complexity $\left(\mathrm{H}_{3}\right)$ appear to not influence their WTP.

The influence of sociodemographic factors is somewhat less clear. The results indicate that home owners with high to medium levels of education seem to prefer solar panels. People in urban areas have a higher WTP for solar water heaters; rural respondents have a higher WTP for solar panels and lower WTP for micro wind turbines. The latter finding is somewhat surprising, as micro wind turbines are likely to work more effectively in a rural setting. The results also show that respondents living in detached houses have a higher WTP for micro wind turbines than people living in semidetached or terraced houses. Home owners in newer and bigger dwellings appear to have a lower WTP for solar panel systems. Apart from these findings, housing characteristics had almost no significant influence on WTP.

\section{Conclusion and policy implications}

The diffusion of microgeneration technologies has great potential to help Ireland in meeting its energy and emission targets and to trigger positive shifts in energy consumption patterns. Yet, despite policy efforts, the rate of adoption among home owners remains low.

The findings presented in this study clearly show that a major reason for the slow uptake is home owners' WTP, which is significantly below market prices. WTP for solar water heaters, which matches current sales figures in Ireland, is the only exception.

More importantly, the results suggest that home owners' purchase or investment decisions are not entirely "rational" but are influenced by factors other than cost-benefit evaluations. Using Rogers' (2003) “innovation decision process" as a theoretical framework, our findings show that home owners' perceptions of product characteristics, social norms and sociodemographic characteristics influence and (partly) account for differences in WTP for the respective technologies.

In relation to annual energy cost savings, home owners are willing to pay most for solar water heaters. They perceive this technology as environmentally friendly, which translates directly into higher WTP. Further, home owners who know someone who operates a solar water system have a higher WTP. This finding indicates that word of mouth is an important vehicle to communicate the benefits of microgeneration and that positive social pressure can translate into higher WTP.

Yet social influence can also have adverse effects. In regard to micro wind turbines, home owners are clearly concerned about the reaction of neighbors and local residents (i.e. social risk). Any effort to promote micro wind power thus needs to address, for example, issues on safety and noise. Also, policy makers and marketers need to further investigate consumer preferences for visually less intrusive and thus more acceptable turbine designs (e.g. vertical versus horizontal design).

Wood pellet boilers are perceived as being difficult to operate, adversely affecting home owners' daily routines and habits. In order to increase WTP for wood pellet boilers, operational requirements could be communicated to home owners more clearly. However, wood pellet boilers are perceived by home owners as a viable alternative to conventional fuels such as oil or gas, which can be communicated as a selling point.

The same is true for solar panels. However, as with wood pellet boilers and wind turbines, initial costs are a major barrier. Any policy aiming to promote microgeneration clearly needs to tackle the high upfront investment. The gap between WTP and actual market prices is large. In this context, public policy in the form of financial incentives such as grant aid or tax incentives can be very costly and might not provide a viable support mechanism for policy makers who aim to promote the diffusion of microgeneration.

Alternative and more market-based options such as consumer finance, leasing and fee-for-service models might thus prove more feasible solutions. "These instruments aim to increase affordability for users by spreading the repayment of the capital costs over longer periods and by reducing the initial payment, and to provide a framework for private initiatives to design and offer their services" (Sustainable Energy Regulation and Policymaking for Africa, no year given).

However, the success of (market-based) support mechanisms depends to a large extent on how programmes are marketed and managed (Stern et al., 1986). The findings presented in this study can thus be utilized by marketers and policy makers to capture the attention of home owners more effectively, overcome their skepticism and apply positive social pressure to ultimately increase people's WTP for microgeneration.

\section{Uncited reference}

Department of the Environment, Heritage and Local Government (2007).

\section{Acknowledgements}

This study was conducted under the umbrella of the Technological Sector Strand III program "Energy Efficient Policy Research in Domestic Buildings". The authors would like to thank the project director Dr Aidan Duffy and the Head of the Futures Academy Dr Ela Krawczyk for their support and reviews of this paper. We also like to thank the Sustainable Energy Authority of Ireland (SEAI) for financing this research.

\section{Appendix A}

\section{See Table A1.}




\section{$1 \quad$ Table A1}

Survey questions.

\section{Construct}

Question

Adapted from

Perceived relative advantages

Environmental friendliness

Independence

Perceived compatibility Habits and routines

Perceived trialability

Perceived complexity

Subjective norms

Perceived initial cost

Compatibility-related costs

Perceived risk

Performance

Perceived risk Social

Subjective knowledge
By installing a $<$ micro wind turbine $>^{\mathrm{a}}$ 오 your house you would help to significantly reduce greenhouse gases By installing a s -micro wind turbine $>$ on your house you would help to improve your local environment

Installing a $<$ micro wind turbine $>$ on your house would make you independent from national energy providers

Installing a $<$ micro wind turbine $>$ on your house would make you self-sufficient

Installing a $<$ micro wind turbine $>$ on your house would reduce your dependence on oil or gas

To use a $<$ micro wind turbine-> $>$ would not require significant changes in your existing daily routines

Using a < $>$ micro wind turbine->> would be compatible with most aspects of your domestic life To use a $>$ micro wind turbine-> $>$ you don't have to change anything you currently do at home You know where you could go to satisfactorily see various types of $<$ micro wind turbine- $>>$ working

You could draw on someone's experience who has installed a $<$ small wind turbine-> $>$ already

$<$ Micro wind turbines-> $>$ are very complex products

$<$ Micro wind turbines- $>>$ would be difficult to use

$<$ Micro wind turbines- $>>$ require a lot of knowledge

You do not have the money to install a $<$ micro wind turbine- $>>$ on your house You would find it a financial strain to install a $<$ micro wind turbine- $>>$ on your house The initial cost of installing a < micro wind turbine-> $>$ on your house would be too high for you

A $<$ micro wind turbine $>$ could only be installed on your house with major additional work In order to install a $<$ micro wind turbine-> $>$ on your house, you'd have to undertake some serious renovation

When thinking about installing a $<$ micro wind turbine-> > on your house you would worry about how dependable and reliable it would be.

When thinking about installing a $<$ micro wind turbine-> $>$ on your house, you would worry about how much ongoing maintenance it would require

When thinking about installing a $<$ micro wind turbine-> > on your house, you would be concerned that they would not provide the level of benefits you would be expecting

When thinking about installing a $<$ micro wind turbine-> > on your house, you would be concerned that your friends would think you were just being showy

When thinking about installing a $<$ micro wind turbine-> $>$ on your house, you would be concerned that some people whose opinion you value would think that you were wasting money

When thinking about installing a $<$ micro wind turbine-> $>$ on your house you would be worried that the local residents might not be happy

Most people who are important to you think that you should install a $<$ micro wind turbine->> on your house

Many people like you will install a $<$ micro wind turbine-> $>$ on their houses

The people in your life whose opinion you value most would encourage you to install a $<$ micro wind turbine->> on your house

Schwarz and Ernst (2008)

Karahanna et al. (2006)

Moore and Benbasat (1991)

Moore and Benbasat

(1991)

a The statements related to micro wind turbines, wood pellet boilers, solar panels and solar water heaters.

\section{References}

Ajzen, I., 1991. The theory of planned behavior. Organizational Behavior and Human Decision Processes 50, 179-211.

Arkesteijn, K., Oerlemans, L., 2005. The early adoption of green power by Dutch households: an empirical exploration of factors influencing the early adoption of green electricity for domestic purposes. Energy Policy 33, 183-196.

Alberini, A., 1995. Efficiency vs bias of willingness-to-pay estimates: bivariate and interval-data models. Journal of Environmental Economics and Management 29 (2), 169-180.

Alberini, A., Kanninen, B., Carson, R., 1997. Modeling response incentive effects in dichotomous choice contingent valuation. Land Economics 73, 309-324.

Allen, S.R., Hammond, G.P., McManus, M.C., 2008. Prospects for and barriers to domestic micro-generation: a United Kingdom perspective. Applied Energy 85 (6), 528-544.
Aprahamian, F., Chanel, O., Luchini, S., 2007. Modeling starting point bias as unobserved heterogeneity in contingent valuation surveys: an application to air pollution. Journal of Agricultural Economics 89, 533-547.

Arrow, K., Solow, R., Portney, P.R., Leamer, E.E., Radner, R., Schuman, H., 1993. Report of the NOAA Panel on Contingent Valuation. National Oceanic and Atmospheric Administration, Washington, DC.

Bang, H.-K., Ellinger, A.E., Hadjimarcou, J., Traichal, P.A., 2000. Consumer concern, knowledge, belief, and attitude toward renewable energy: an application of the reasoned action theory. Psychology and Marketing 17, 449-468.

Batley, S.L., Fleming, P.D., Urwin, P., 2000. Willingness to pay for renewable energy: implications for UK green tariff offerings. Indoor and Built Environment 9,157-170.

Berkowitz, M.K., Haines, G.H., 1980. Multi-attribute analysis of solar and other space heating preferences. In: Claxton, J.D., Anderson, C.D., Ritchie, J.R.B. McDougall, G.H.G. (Eds.), Consumers and Energy Conservation: International Perspectives on Research and Policy Options. Praeger, New York, pp. 108-114. 
Borchers, A.M., Duke, J.M., Parsons, G.R., 2007. Does willingness to pay for green energy differ by source? Energy Policy 35 (6), 3327-3334.

Cameron, T., Quiggin, J., 1994. Estimation using contingent valuation data from a "dichotomous choice with follow-up" questionnaire. Journal of Environmental Economics and Management 27, 218-234.

Carson, R.T. Hanemann, W.M., Mitchell, W.C., 1986. Determining the demand for public goods by simulating referendums at different tax prices. Manuscript, University of California, San Diego, unpublished.

Claudy, M.C., Michelsen, C., O’Driscoll, A., Mullen, M.R., 2010. Consumer awareness in the adoption of microgeneration technologies: an empirical investigation in the Republic of Ireland. Renewable and Sustainable Energy Reviews 14 (7) 2154-2160.

Cooper, J., 1994. A comparison of approaches to calculating confidence intervals for benefit measures from dichotomous choice contingent valuation surveys. Land Economics 70, 111-122.

Cooper, J.C., Hanemann, W.M., 1995. Referendum contingent valuation: how many bounds are enough? Working Paper, USDA Economic Research Service, Food and Consumer Economics Division, Washington, DC.

Darley, J.M., Beniger, J.R., 1981. Diffusion of energy conserving innovations. Journal of Social Issues 37, 150-171.

Department of Communications, Marine and Natural Resources, 2007. Delivering a sustainable energy future for Ireland. Government White Paper, Government Stationery Office, Dublin.

Department of the Environment, Heritage and Local Government, 2007. Ireland National Climate Change Strategy 2007-2012. Government Stationery Office Dublin.

DeShazo, J., 2002. Designing transactions without framing effects in iterative question formats. Journal of Environmental Economics and Management 43, 360-385

Dholakia, U.M., 2001. A motivational process model of product involvement and consumer risk perception. European Journal of Marketing 35 (11/12) 1340-1360.

Ek, K., 2005. Public and private attitudes towards "green" electricity: the case of Swedish wind power. Energy Policy 33 (13), 1677-1689.

Energy Saving Trust, 2005. Potential for microgeneration study and analysis. Fina report, Department for Business, Enterprise and Regulatory Reform, London.

ESTIF, 2009. Solar thermal markets in Europe: trends and market statistics 2008 . European Solar Thermal Industry Federation, Brussels.

Faiers, A., Cook, M., Neame, C., 2007. Towards a contemporary approach for understanding consumer behaviour in the context of domestic energy use. Energy Policy 35 (8), 4381-4390.

Frondel, M., Ritter, N., Schmidt, C.M., 2010. Die Förderung der Photovoltaik: Ein Kosten-Tsunami. Energiewirtschaftliche Tagesfragen 60 (11).

Garcia, R., Calantone, R., 2002. A critical look at technological innovation typology and innovativeness terminology: a literature review. Journal of Product Innovation Management 19 (2), 110-132.

Haab, T., McConnell, K., 2003. Valuing Environmental and Natural Resources: The Econometrics of Non-market Valuation. Edward Elgar, Northampton, UK.

Hanemann, M., Loomis, J., Kanninen, B., 1991. Statistical efficiency of doublebounded dichotomous choice contingent valuation. American Journal of Agricultural Economics 73 (4), 1255.

Hansla, A., Gamble, A., Juliusson, A., Garling, T., 2008. Psychological determinants of attitude towards and willingness to pay for green electricity. Energy Policy 36 (2), 768-774.

Hastings, G., 2007. Social Marketing. Why Should the Devil Have All the Best Tunes. Butterworth-Heinemann, Oxford

Hübner, G., Felser, G., 2001. Fuer Solarenergie-Konsumenten- und Umweltpsychologie strategisch anwenden. Ansanger Verlag, Heidelberg, Germany.

Karahanna, E., Agarwal, R., Angst, C.M., 2006. Reconceptualising compatibility beliefs in technology acceptance research. MIS Quarterly 30 (4), 781-804.

Kimenju, S.C., De Groote, H., 2008. Consumer willingness to pay for genetically modified food in Kenya. Agricultural Economics 38, 35-46.

Kleijnen, M., Lee, N., Wetzels, M., 2009. An exploration of consumer resistance to innovation and its antecedents. Journal of Economic Psychology 30 (3), 344-357.

Klerck, D., Sweeney, J.C., 2007. The effect of knowledge types on consumerperceived risk and adoption of genetically modified foods. Psychology and Marketing 24 (2), 171-193.

Koundouri, P., Kountouris, Y, Remoundou, K, 2009. Valuing a wind farm construction: a contingent valuation study in Greece. Energy Policy 37 (5), 1939-1944.

Krinsky, I., Robb, L., 1986. On approximating the statistical properties of elasticities. Review of Economics and Statistics 68, 715-719.

Labay, D.G., Kinnear, T.C., 1981. Exploring the consumer decision process in the adoption of solar energy systems. Journal of Consumer Research 8 (3). $271-278$.
Louviere, J.J., Hensher, D.A., Swait, J.D., 2000. Stated Choice Methods: Analysis and Applications. Cambridge University Press, Cambridge, UK.

Mitchel, R., Carson, T., 2003. Using Surveys to Value Public Goods: The Contingent Valuation Method, 4th ed. Resources for the Future, Washington, DC.

Moore, G.C., Benbasat, I., 1991. Development of an instrument to measure the perceptions of adopting an information technology innovation. Information Systems Research 2, 192-222.

Mukherjee, A., Hoyer, W.D., 2001. The effect of novel attributes on product evaluation. Journal of Consumer Research 28 (3), 462-472.

Nomura, N., Akai, M., 2004. Willingness to pay for green electricity in Japan as estimated through contingent valuation method. Applied Energy 78 (4), 453-463.

Nunnally, J.C., 1978. Psychometric Theory, 2nd ed. McGraw-Hill, New York

Nyrud, A.Q., Roos, A., Sande, J.B., 2008. Residential bioenergy heating: a study of consumer perceptions of improved woodstoves. Energy Policy 36 (8), 3169-3176.

Observ'ER, 2009. Photovoltaic energy barometer-EuroObserv'ER. Qbserv'ER, Paris.

O’Doherty, J., Lyons, S., Tol, R.S.J., 2008. Energy-using appliances and energy-saving features: determinants of ownership in Ireland. Applied Energy 85 (7), 650-662.

Ojea, E., Loureiro, M.L., 2007. Altruistic, egoistic and biospheric values in willingness to pay (WTP) for wildlife. Ecological Economics 63 (4), 807-814.

O’Leary, F., Howley, M., Q Gallachóir, B., 2008. Energy in the Residential Sector. SEAI, Dublin.

Pearce, D., Atkinson, G., Mourato, S., 2006. Cost-benefit Analysis and the Environment: Recent Developments. OECD, Paris.

Peter, J.P., Tarpey, L.T., 1975. A comparative analysis of three consumer decision strategies. Journal of Consumer Research 2, 29-37.

Pollard, M., Kalafatis, S.P., East, R., Tsogas, M.H., 1999. Green marketing and Ajzen's theory of planned behavior: a cross-market examination. Journal of Consumer Marketing, 16

Porter, C.E., Donthu, N., 2006. Using the technology acceptance model to explain how attitudes determine Internet usage: the role of perceived access barriers and demographics. Journal of Business Research 59, 999-1007.

Ready, R., Buzby, J., Hu, D., 1996. Differences between continuous and discrete contingent value estimates. Land Economics 72, 397-411.

Rogers, E.R., 2003. Diffusion of Innovation, 5th ed. Free Press, New York

Scarpa, R., \& Bateman, I. (1998). Does a third bound help? Parametric and nonparametric welfare measure from a CV interval data study. Working Paper No. 51.98, Fondazione Eni Enrico Mattei, Milan, Italy.

Scarpa, R., Willis, K., 2010. Willingness-to-pay for renewable energy: primary and discretionary choice of British households for micro-generation technologies. Energy Economics 32 (1), 129-136.

Schultz, S., Lindsay, B., 1990. The willingness to pay for groundwater protection. Water Resources Research 26, 1869-1875.

Schwarz, N., Ernst, A., 2008. Die Adoption von technischen Umweltinnovationen: Das Beispiel Trinkwasser. Umweltpsychologie 22 (1), 28-48.

Sorrell, S., O'Malley, E., Schleich, J., Scott, S., 2004. The Economics of Energy Efficiency: Barriers to Cost-effective Investment. Edward Elgar, Cheltenham, UK.

Spash, C.L., Urama, K., Burton, R., Kenyon, W., Shannon, P., Hill, G., 2008. Motives behind willingness to pay for improving biodiversity in a water ecosystem: economics, ethics and social psychology. Ecological Economics 68, 955-964.

Stern, P.C., 1999. Information, incentives and proenvironmental behaviour. Journal of Consumer Policy 22, 461-478.

Stern, P.C., Aronson, E., Darley, J.M., Hill, D.H., Hirst, E., Kempton, W., Wilbanks, T.J., 1986. Answering behavioral questions about energy efficiency in buildings. Energy 12, 339-353.

Stone, R.N., Grønhaug, K., 1993. Perceived risk: further considerations for the marketing discipline. European Journal of Marketing 27 (3), 39-50.

Sustainable Energy Regulation and Policymaking for Africa, no year given. Module 20: financing options for renewable energy and energy efficiency. Available from $\langle$ www.afrepren.org $\rangle$

Tornatzky, L.G., Klein, K.J., 1982. Innovation characteristics and innovation adoption-implementation: a meta-analysis of findings. IEEE Transactions on Engineering Management 29 (1), 28-45.

Verhoef, P.C., Franses, P.H., 2002. On combining revealed and stated preferences to forecast costumer behavior: three case studies. Econometric Institute Report, 2002-04. Erasmus University, Rotterdam, The Netherlands.

Wiser, R.H., 2007. Using contingent valuation to explore willingness to pay for renewable energy: a comparison of collective and voluntary payment vehicles. Ecological Economics 62 (3-4), 419-432.

Yoo, S.-H., Kwak, S.-Y., 2009. Willingness to pay for green electricity in Korea: a contingent valuation study. Energy Policy 37 (12), 5408-5416.

Zarnikau, J., 2003. Consumer demand for 'green power' and energy efficiency. Energy Policy 31 (15), 1661-1672. 